\title{
Science and scientists turned into news and media stars by scientific journals. A study on the consequences on the present scientific behaviour
}

\author{
Carlos Elías
}

This article explores whether some scientists have now actually been developing a type of science apt to be published as a piece of news, yet lacking a relevant scientific interest. Possibly, behind this behaviour there may be the present working culture, in which scientists live under the pressure of the dictatorship of the Science Citation Index (SCI) of the reference journals. This hypothesis is supported by a study demonstrating that there is a direct relation between publishing scientific results in the press and a subsequent increase in the SCI index. Many cases are here described, selected among the papers published in Nature that - according to experts - have a media interest rather than a scientific one. Furthermore, the case of the Dolly sheep cloning is studied as a paradigm for a situation in which media coverage actually destroyed the research group.

\section{Context}

The present scientific context hardly allows to establish who is a good scientist producing quality science. Given the lack of more sophisticated systems - or of the test of time of the future History of Science -, scientists judge one another on the basis of their publications and, most of all, of the Science Citation Index (SCI), as well as the number of citations of any work or scientist. The problem is that this citations system may be distorted if scientific studies are the subject of media news. This circumstance was demonstrated in 1991 in a phenomenal study published in the New England Journal of Medicine, whose authors (Phillips et al.) analysed the papers published in that journal between 1978 and 1979 and compared those having subsequently appeared in The New York Times with those that had not. ${ }^{1}$ According to their reports, the studies published in the US newspaper had been cited by 72.8 per cent more in the year following to their publication than those not appearing on that newspaper. The most important aspect is that a significant difference in citations persisted at least for ten years subsequent to the publication of the scientific results in the paper. And everybody knows what citations and the impact index are to the academic career of a scientist. The goal of this paper is to establish whether this event can drive a scientist to select their research area on the basis of the likely media coverage, instead of the opportunity to know nature better.

The study by Phillips included a very well devised verification system to prove the assumption justifiable from a journalistic viewpoint - that The New York Times was only providing information on the most significant scientific results, which would obviously have received more citations in any case. But Phillips and his collaborators were lucky, or had devised a very good strategy to illustrate their methodology. Indeed, during the period under study, The New York Times had to face a three-month strike (1978) of its staff. However, during that strike, the newspaper produced some issues to be kept in a "record edition", although none of them was distributed to the public. The authors of the work analysed that "record edition" to check what news The New York Times considered worth of coverage, even though the paper was not being published.

The study demonstrated that the papers deserving a highlight, yet not published because of the strike, had not seen an increase in the quantity of citations in the following years. Thus, it was demonstrated that a scientific paper mentioned in the quality press is cited by 78.2 per cent more, irrespective of the quality of the research. These results are in line with another study which demonstrated that 60 per cent of the members of the Wisconsin Medical School learned about new scientific breakthroughs through the 
media. ${ }^{2}$ Another study provided an even higher percentage in the case of North Carolina physicists: 89 per cent of them stated in a survey that they learned about new scientific breakthroughs outside their field through the media. ${ }^{3}$

Consequently, another fact is demonstrated: it is scientists themselves - and not much journalists - who are most interested, in terms of professional promotion, in disseminating their research works through the quality press.

Moreover, as the impact index of a journal is measured depending on the number of citations of its papers on other publications, if a journal manages to spread them in the press, the following year it will have a higher SCI index. It implies that the best scientists will ask to publish in it, and this circle mechanism will increasingly favour this trend. Hence, this is why major science journals such as Nature or Science invest much in their press offices, in their media communication and, furthermore, their public relations are so important. The result is a St. Matthew effect: "For unto every one that hath shall be given, and he shall have abundance: but from him that hath not shall be taken away even that which he hath".

But a distortion is created, as only Nature and Science and some medical journals have very professional press offices that really know how journalism works. As a consequence of this media knowhow, their publications will be given a higher SCI day after day and the remainder will irremediably stay put in lower places. Nature moved from a 28.8 impact in 1998 to a 32.12 one in 2004.

Somebody may say: and so what? Let the other journals copy the strategy of Science and Nature. At this point, that is not an easy task, as media and scientists both consider them as the best and, consequently, they will try to publish their best works there, as they know those journals are an unquestionable evidence of quality. As the best works are addressed to them, also journalists feel confident when selecting their press notes. In order to make readers grasp the importance of these two journals on those occasions, I will now list the criteria for the international ranking of the 500 best universities in the world, processed since 2004 by the Institute of Higher Education of Shanghai: Nobel laureates who have given classes there, the number of Nobel laureates educated there and, finally, the number of papers their lecturers have published in Nature and Science. This means that publications in those journals are needed to achieve a higher ranking. ${ }^{4}$

It should be made clear that those journals are not specialised and that their main goal is obviously to publish the best science, but also to have the best impact index. As a consequence, many times it is journalism criteria that dictate when they select their papers, not much for the press release, but in the actual acceptance of the scientific paper, which can really be a distortion of the scientific system.

\section{Methodology}

In order to demonstrate this hypothesis, a selection was carried out among a number of research studies from a scientific journal held as one of the best in the world: Nature. As we wanted to demonstrate these two approaches - a research being journalistically relevant, or a scientist turning into a media star papers were chosen depending on their journalistic quality. Then, the selection was submitted to three Spanish scientists working in the field. They had the task of rating the scientific interest of the papers on a scale from 0 to 10 . The "study cases" included only those that, despite having been published in Nature, were given a rating under 5 out of 10 . The only exception was the article on cloning Dolly the sheep, because in that specific case we wanted to assess the professional repercussions a scientist may have after becoming a "media star".

\section{Result 1: science devised with a view to receive media coverage}

The first example may be the article published in Nature on January, $4^{\text {th }} 1996$ about the analgesic effects of myrrh. ${ }^{5}$ The article, according to the three experts, had a scientific relevance of 2.9. However, it was published on the week celebrating the Christian holiday of the Three Kings. The headline of the study of Nature was typically descriptive, as in scientific articles - "Analgesic effects of myrrh" -, but in the press release, Nature titled the work as follows: "Why did the Three Kings carry myrrh?". Obviously, the piece of news was selected by many media because it perfectly fitted the current issues of that week. First came the newspapers and then - as usually is the case with scientific journalism - echoes of the piece of news reached radio and TV broadcasters. 
In 2003, Nature Neuroscience also published a surprising piece of news on the "cells of the human soul" picked, among others, also by the newspaper The Sunday Times and by the Spanish El Mundo. ${ }^{6}$ Only a month earlier, on the $13^{\text {th }}$ of February, Nature had published a study containing the following conclusion: "The majority prefer to kiss rightwards". ${ }^{7}$ However, it was the conclusion of the Nature press office. In fact, the article - which only fell into the "brief communication" category - was titled "Human behaviour: adult persistence of head-turning asymmetry" ${ }^{\prime \prime}$. Nevertheless, the press office is not entirely guilty in this case. The research methodology, mentioned in the scientific paper, explained that the researcher had observed "how couples kiss in public places (airports, train stations, beaches and gardens) in the US, Germany and Turkey." This is terrible because the image that the scientist himself offers to society is the one of a voyeur hiding his pathology behind a scientific mask. Not far from the archetype of the nutty and unloved scientist conveyed by cinema. The perception sensed by young people - and not so young - listening to this piece of news is that "in the real world, people kiss like in the real world and scientists only are there to observe how other people kiss and not to kiss themselves. And they are satisfied with it." And this is in the best of cases. In the worst, a scientist is compared to a sexual pervert.

I believe that, even though the study might have been serious - the experts rated it 4.2 -, personally I would not have included it in an academic journal. In fact, not only was it included, but it was the top piece of news selected by the press office (and by the media all over the world) out of the issue of that week (no. 421) which, among others, included studies on autoimmunity, quantum gravity, an analysis on the proteins movement in cells, the origins of carnivores in Madagascar, the role played by interleukin23 in brain inflammation or the effects on the Great Barrier Reef sediments by the European colonisation in Australia. As a general rule, newspapers or TV news only have space for a single scientific piece of news a day, and the one which conquered that space was the one about "kissing rightwards." And, possibly, its author will also receive more citations in the following ten years and make more money through competitive projects. This is a wicked effect for science, whose origin lies in the media culture.

Without any doubts, all of this contributes to spreading a caricature-like image of science. Who is to blame? Journalists, who simply transcribe what researchers guarantee, or scientists, who in their turn exploit them to improve their curriculum and to be more prestigious in the eyes of their colleagues? It should not be disregarded. The broad coverage given to irrelevant topics, and the increase in the quotations that it provokes after their publication in the press, will lead many scientists to study side effects of science with a journalistic appeal rather than core science itself. Hundreds of scientists all over the world studying the analgesic effects of many substances will include in their references the article on myrrh published by Nature. Consequently, an article - initially irrelevant - will become important and its authors will earn honours through the present researcher evaluation system ruling all over the world.

The executive editors of major journals do acknowledge that, because of this dictatorship, they often publish studies which are relevant from a scientific point of view, but not from a methodological one. Indeed, Richard Smith, in his memoirs on a twenty-five year career - thirteen of which as an editor spent in one of the most prestigious medical journals, the British Medical Journal, acknowledges that frequently strictly scientific criteria are not the most important: ${ }^{9}$

"I recall a debate on an article we published in our Christmas issue, traditionally devoted to slightly weird, absurd or funny topics. A long monitoring on the Welsh population demonstrated that 40 -year-old men who had had fifty orgasms a year lived longer than those who had had less orgasms than that. ${ }^{10}$ Quite inevitably, doubts were raised on those data. What honesty could be expected from people questioned about their sex life? Perhaps the factor causing men to have more orgasms was simply a result of other characteristics that made them more apt to live longer. Or maybe healthier men could have more orgasms. That study was irrelevant in medical and scientific terms, yet it could be of interest to our readers and achieve a broad media coverage. I decided to publish that study, and it won broad coverage (Smith, 2006: 181)".*

These behaviours from the journals, contaminated by a journalistic culture, will drive some scientists owing to the increasing competitiveness they are subjected to - to drop studying some tedious issues which have limited prospects of becoming news, even though they are relevant in terms of scientific corpus, and to focus their studies on the side effects of those issues. The next few years will witness the conclusions of "wise" studies being published in "prestigious" journals about the consequences of a

\footnotetext{
* Translator's note: this quote is not taken from the original English text, but it is a translation from the Spanish paper.
} 
meteorite impact on the Earth, the chemical substance making people fall in love, the star that led the way of the Three Kings, the happiness equation, the likely antiangiogenetic properties of the oddest food, from wine and grapes to olive oils and chocolates. All of them turned into issues suitable for research, discarding other issues more scientifically relevant, yet less media-appealing.

\title{
Result 2: the scientist as a media star: the Wilmut case
}

Another perspective of the relation between media-major journals and the likely distortion in the scientific method can be observed analysing the entire media fuzz surrounding one of the most important scientific breakthroughs of the past few years: the cloning of the Dolly sheep. At that time, it was considered as "very relevant" both in the Nature summary and in its press office. Its publication in Nature on February $27^{\text {th }}, 1997$, aside from provoking a large debate in the society on cloning, implied a very-well devised design on the way to communicate the news, with a view to achieve a controlled, yet global, impact on the media. It may appear as an oxymoron. The communication strategy, the impact and the way this piece of news was treated in the media can be rightfully considered as a paradigmatic case of public science communication. For instance, the archetype of the scientist having no qualms was repeated again. The oddest opinion makers with no trace of a scientific education filled pages and pages in the newspapers, whereas those actually having some expertise on the issue shut themselves away, scared, in their laboratories, waiting for the storm to end.

However, I am now interested in analysing the effect this media stress had on the scientists who created Dolly and, more in general, on science as a whole. The first consequence was the disruption of the research team. This team, from the Roslin Institute of Edinburgh, Scotland, worked under the supervision of Ian Wilmut, in close cooperation with the communication advisors of PPL Therapeutics, a company which funded and cooperated with the cloning project. So, when Nature confirmed the publication of the article, the communication team had only ten days at disposal to plan the media strategy. The PR department of the press office of Nature and PPL Therapeutics appointed Ian Wilmut as a spokesperson. The media culture does need heroes or villains, but it always prefers individuals rather than groups. Two experts in media communication were sent out from London to Edinburgh to give advice on the TV broadcasting. The result was obvious: the appointed spokesman was turned into a media star and it is still shining.

The Dolly scientists knew that Nature would have included their research in the weekly press release distributed on that Friday, containing information to be held back until the following Wednesday, to be finally published on Thursday. However, they received two phone calls on Saturday night alerting them that The Observer would have published the story on the following day, three days earlier than planned. In the span of only a week, they received over 2,000 phone calls, met approximately one hundred journalists and the access to Dolly was granted to sixteen television crews and over fifty photographers from all over the world.

How did Wilmut cope with this media impact? Curiously enough, during an interview, the subject of Wilmut's criticism was not the media, but the system spreading to media the results of the studies published by Nature. Wilmut defines as "unfortunate" the system by which Nature and other journals keep research studies secret until their publication. ${ }^{11}$

\begin{abstract}
"This strategy - says Wilmut - implies a slowdown in the discussion on your work. It also magnifies and amplifies facts when information surfaces, so that the media provide excessive feedback. The process could be improved if research results were discussed more openly. This way, once you have an article, it could be specifically developed for Nature, for example. But in order to protect their exclusivity position, some journals would not approve this method."

(Wilmut in Quark, no. 14: 80)
\end{abstract}

Wilmut's statement is really interesting given that, though Nature self-proclaims the "great defender" of science, obviously it still is a private company. Therefore, quite logically, as any other medium, it wants a good exclusive rather then losing it for the sake of a more rigorous work or to favour a debate on the issue among scientists. The behaviour of Nature is ferocious - it threatens to withdraw the article publication - with those not complying its rule that a research published by the journal cannot be cited in

\footnotetext{
${ }^{\dagger}$ Translator's note: this quote is not taken from the original English text, but it is a translation from the Spanish paper.
} 
any other place. Thus, the publication of a scientific result turns into what is called a scoop in journalism. It boosts the multiplying effect in the media, as they know they are surfacing an unpublished piece of news, previously undisclosed. Precisely as maintained by Wilmut, in the end, all of this is detrimental to the scientific debate, so much required by the scientific method.

With respect to the extraordinary impact of the news on the Dolly cloning, the editor in chief of Nature in 1997, Phillip Campbell, assured during an interview that neither the Nature editorial office, nor the revisers of the study had foreseen the actual impact the news had. "In fact, says Campbell, a similar study, though involving foetal cells, had already been published a year earlier and it had gone almost unheeded."

However, Campbell forgot to clarify that in the case of Dolly the communication advisors of PPL Therapeutics - who were the people funding the study - wanted free advertising on the media. To that purpose, they outlined a strategy which was quite successful: to ask scientist to talk about the feasibility of future human cells cloning, something that was not even mentioned as a distant possibility in the study published in Nature.

But a piece of news without controversy "does not sell" and scientists, advised by journalists, gave in: they accepted to talk about the human repercussions, only to fill the newspapers front pages. Indeed, in the quoted interview, Wilmut acknowledges that the pressure by the media was even positive, because thanks to the direct benefits stemming from the publicity on the discovery "it has been easier to find resources to start up a company to take advantage of the technique used to create Dolly."

\section{The spokesman turns into an important researcher}

You do not need to be an expert of science history to know that, except some cases in mathematics, starting from the 20th century, only a few breakthroughs have been made by a single individual. This is what is called professionalisation - some call it taylorisation - of science. However, given the idiosyncrasy of the media not to focus their attention on a "set" of protagonists, normally one of the scientists is selected as a "spokesperson" for the media. When the piece of news is important - as was the case with Dolly - the spokesperson turns into a popular scientist - a star -, with all the benefits and harms it implies. As soon as Nature sends out its press release all over the world, the scientist becomes a global media star. Is all of this positive for science? In the case of the research team that achieved the breakthrough of the Dolly, the result of the media coverage was its disruption.

In 2006, the British press informed about the legal action taken against Ian Wilmut for "having embezzled the Dolly cloning work and having prevented his collaborators from achieving the honours they deserved." The legal action, which deserves to be the subject of a book or of a doctoral thesis on its own, was fascinating as it made the $21^{\text {st }}$-century science dynamics plain to see. It was at the tribunal hearing that Wilmut admitted that he had played only a minor role in the cloning breakthrough, yet he had been given all the credit by the media. This is different from the Korean scientist Hwang Woo-suk case, who in fact manipulated data, because Dolly the sheep really existed. However, both are connected as they demonstrate the fierce competition and aggressiveness existing in present-day science, frequently due to the contamination by the media culture.

The tribunal hearing took place in Edinburgh in March 2006; not only did it win a broad media coverage in Great Britain, but it was also commented within the academia. The trial originated from a Wilmut's collaborator, cell biologist Keith Campbell, who believed that he was professionally mistreated by Wilmut. Wilmut had to admit, facing the evidence provided by Campbell, that "Campbell deserved at least 66 per cent of the credit for Dolly." Nonetheless, Campbell appeared at the bottom of the paper published in the journal Nature, while Wilmut insisted on putting his own name at the beginning.

The second author having signed that paper, Angelika Schieke - at that time a doctor's degree student told The Scientist that Wilmut was given such a prominent role because in a previous meeting he had asked for it and the team members did agree, though that prominent role hardly corresponded to his actual contribution. While the trial against Wilmut was ongoing, the press reported the complaints from the two laboratory technicians who performed the painstaking manipulation of the sheep cells and embryos, whose final result was Dolly. In fact, they believed that the merit of Dolly was not a new interpretation of a natural process or a pure scientific breakthrough, but it was basically a technical application. However, even the technique was not a novelty, as it had been described before. The achievement of Dolly, according to the technicians heard in the trial, was the repeated application of a well-known technique to hundreds of samples, until one succeeded. This is why they also believed they 
had not been given the credit they deserved. In general, the research team complained that, in the media coverage on Dolly, it seemed as if Wilmut had conceived the idea - something which was not certain and had worked all day long in the laboratory as a modern Madam Curie - which was not the case, as they stated during the trial. What was his merit? Having selected technicians and scholars and having found some money? Does it deserve all the scientific honours?

\title{
Conclusions
}

All of this drives us to consider that in present scientific results do not have a clear protagonist and that researchers frequently exploit the media to achieve an importance they do not really have, in scientific terms. However, media fame does work for the modern renown of a scientist. In fact, among the members of the Dolly team, only Wilmut was given the prestigious German prize Paul Erlich. On top of that, Wilmut was appointed director of the new Centre for Regenerative Medicine of the University of Edinburgh, one of the few which have been given a go-ahead to clone human embryos by the British government. In other words, the media effect worked in favour of Wilmut, but not in favour of the scientist who had worked the most on the project, Campbell - who contributed 66 per cent of the work.

Is this the usual practice? It has always occurred, yet the media culture favours it. Indeed, in the same research field, in the same country and in the same period, something similar took place. The case happened at Newcastle University, the first centre ever to have obtained an authorisation to clone human embryos. In 2005, the Serbian scientist Miodrag Stojkovic left that University as soon as he discovered in the media that his chief, Alison Murdoch, rushed in a press conference to present the results of the first human embryo on which they had worked together. The worst thing to Stojkovic was the fact that during the press conference Murdoch received most part of the credit; the Serbian scientist believed he had actually given the most important contribution to the breakthrough.

In any case, the purpose of this paper is to suggest that the interaction of science with the media, instead of being beneficial, may actually be highly detrimental.

Translated by Massimo Caregnato

\section{Notes and bibliography}

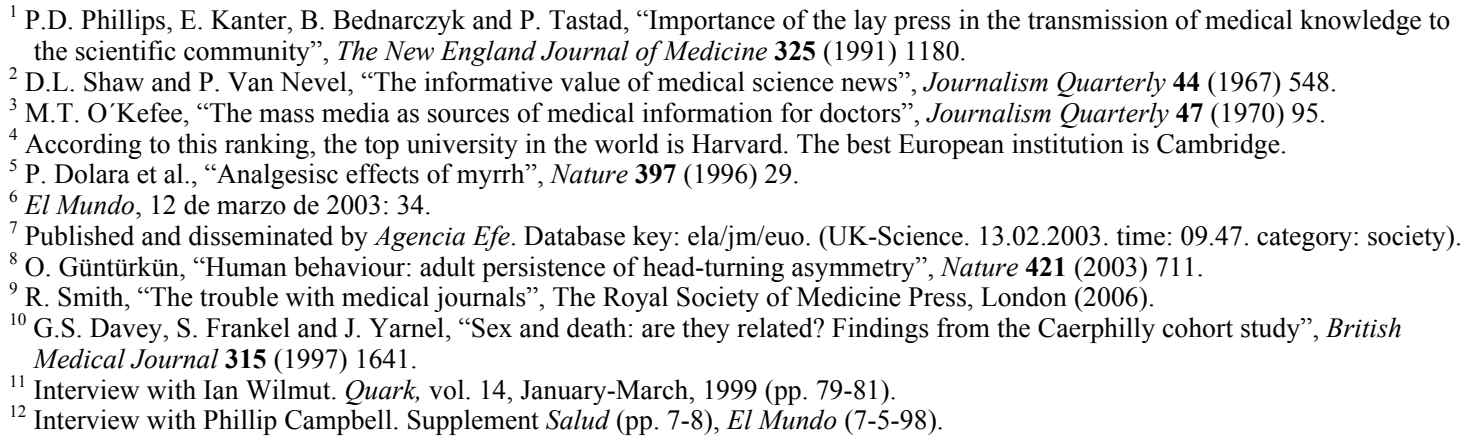

\begin{abstract}
Author
Carlos Elías is Senior Lecturer in Scientific Journalism at University Carlos III of Madrid, and he was Visiting Fellow at London School of Economics (2005/2006). Educated in Chemistry (MA) and Journalism $(\mathrm{PhD})$ at the University of La Laguna, he worked as a political journalist for EFE News Agency and as scientific correspondent for El Mundo. His research focuses on the relationship between policy-making, science and mass media culture. He has published several scientific articles and three books in this field. His latest book is Reason Strangled: The Science Crisis in the Contemporary Society (Debate/Ramdom House Modadori, 2008). E-mail: celias@hum.uc3m.es.
\end{abstract}

